\title{
Urban Aerodynamic Roughness Length Mapping Using Multitemporal SAR Data
}

\author{
Fengli Zhang, ${ }^{1}$ Minmin Sha, ${ }^{1,2}$ Guojun Wang, ${ }^{1}$ Zhikun Li, ${ }^{1,2}$ and Yun Shao ${ }^{1}$ \\ ${ }^{1}$ Institute of Remote Sensing and Digital Earth, Chinese Academy of Sciences, A20 North, Datun Road, Beijing 100101, China \\ ${ }^{2}$ University of Chinese Academy of Sciences, Beijing 100049, China \\ Correspondence should be addressed to Fengli Zhang; zhangfl@radi.ac.cn
}

Received 8 September 2016; Accepted 9 January 2017; Published 31 January 2017

Academic Editor: Enrico Ferrero

Copyright (c) 2017 Fengli Zhang et al. This is an open access article distributed under the Creative Commons Attribution License, which permits unrestricted use, distribution, and reproduction in any medium, provided the original work is properly cited.

\begin{abstract}
Aerodynamic roughness is very important to urban meteorological and climate studies. Radar remote sensing is considered to be an effective means for aerodynamic roughness retrieval because radar backscattering is sensitive to the surface roughness and geometric structure of a given target. In this paper, a methodology for aerodynamic roughness length estimation using SAR data in urban areas is introduced. The scale and orientation characteristics of backscattering of various targets in urban areas were firstly extracted and analyzed, which showed great potential of SAR data for urban roughness elements characterization. Then the ground truth aerodynamic roughness was calculated from wind gradient data acquired by the meteorological tower using fitting and iterative method. And then the optimal dimension of the upwind sector for the aerodynamic roughness calculation was determined through a correlation analysis between backscattering extracted from SAR data at various upwind sector areas and the aerodynamic roughness calculated from the meteorological tower data. Finally a quantitative relationship was set up to retrieve the aerodynamic roughness length from SAR data. Experiments based on ALOS PALSAR and COSMO-SkyMed data from 2006 to 2011 prove that the proposed methodology can provide accurate roughness length estimations for the spatial and temporal analysis of urban surface.
\end{abstract}

\section{Introduction}

Urban areas occupy only a very small fraction of the Earth's land area, yet $60-80 \%$ of final energy and concentrate materials, wealth, and innovation is consumed in urban areas. With rapid urbanization, the population of urban areas has exceeded rural areas in the past decade [1]. The increased amount of roughness elements, which are mainly composed of buildings and road networks in urban areas, dramatically alters the surface roughness and urban boundary layer dynamics [2], which in turn results in more frequent air pollution and extreme weather. More specifically, the increased drag and enhanced turbulent momentum flux result in reduced wind speeds within the urban boundary layer. The drag effect of roughness elements is very important for urban mesoscale numerical models and it is usually parameterized using an aerodynamic roughness length. Aerodynamic roughness length is usually defined as the height where the wind velocity is equal to zero. It is an important aerodynamic parameter and reveals the exchange between the atmosphere and land surfaces. Precise mapping of aerodynamic roughness in urban areas is crucial for different modeling applications, like urban climate or air quality studies, as well as for planning purposes such as the identification of potential ventilation paths [3]. Nevertheless, urban areas are the roughest of all aerodynamic boundaries, and the spatial distribution of roughness elements in urban areas is highly heterogeneous [4]. It is very difficult to quantitatively retrieve the aerodynamic roughness in urban areas and its study is in a very preliminary stage [5].

Most of the conventional methods used in aerodynamic roughness calculations are meteorological methods, which utilize the wind and temperature gradient data acquired by flux towers or meteorological stations. The cost of this approach is great, and the calculated aerodynamic roughness length only represents a very small extent of an entire urban area. Other kinds of methods calculate aerodynamic roughness using morphological methods according to the height, distribution, and frontal areas of the roughness elements. Nevertheless, most current methods assume that the height 
of roughness elements is the same and they are distributed evenly, which is very different to the actual high degree of heterogeneity that is presented in urban areas. Infrastructure spatial data and LiDAR data are anticipated to overcome this limitation, yet this kind of data is expensive and its update period is very long, which restricts its application within very small areas. As such, there is an urgency to find an effective method for the aerodynamic roughness mapping in urban areas [6].

Synthetic Aperture Radar (SAR) is anticipated to provide a valuable tool for roughness mapping because the backscattering received by the SAR sensor is sensitive to the geometric structure of the target, which in turn is directly related to surface roughness. And SAR data has been used for aerodynamic roughness retrieval of uniform surfaces, such as deserts and vegetation areas [5, 7]. Yet aerodynamic roughness estimation in urban areas is very difficult because of the high heterogeneity of roughness elements, and the challenges related to high heterogeneity of urban areas still need to be resolved. The current methods for urban roughness mapping can be classified into three categories.

The first category maps the aerodynamic roughness through first classifying SAR images and then specifying roughness values for each class according to a look-up table. One of the most famous methods is Davenport method [8], yet the 8 classes can not precisely describe the roughness elements in urban areas. Zoran used multiple SAR images to map urban aerodynamic roughness through precisely identifying non-built-up areas, residential areas, industry areas, and large groups of buildings [9]. Stetson estimated the aerodynamic roughness length in Houston metropolitan area through applying a coefficient to the commonly used roughness length of a given class, which was determined according to the quotient of a pixel's backscattering and the mean backscattering of the corresponding land use type [10]. Bidaut et al. used multitemporal SAR images for supervised classification and then mapped the urban aerodynamic roughness using a look-up table for each land use class [11]. This is the most widely used method, yet it is not suitable for mesoscale models because urban areas need more precise classification results and yet it is very difficult because urban areas are highly heterogeneous.

The second category calculates aerodynamic roughness using a morphological method that utilizes the geometric parameters of roughness elements such as the height, plan area index, and front area index. Basly et al. mapped the aerodynamic roughness of Nantes using ERS images through extracting structural features and land use class attributes [12]. Bechtel et al. used interferometric SAR data to extract the topology, statistics, and texture of roughness elements and then used the mean and the variance of the height of the roughness elements within a sector to map the aerodynamic roughness in urban areas [13], and Langkamp further analyzed the effect of various dimension of sector area on aerodynamic roughness retrieval [14]. This kind of method exerts strict requirements for the precision of interferometric measurements which is generally regarded very difficult for urban areas.
The last category tries to build a quantitative relationship between aerodynamic roughness and SAR backscattering. Jeyachandran et al. first analyzed the correlation between SAR backscattering and the urban canopy parameters such as the mean height, plan area fraction, and frontal area index of roughness elements in urban areas and then built exponential relationship model between the SAR backscattering and the aerodynamic roughness length [15]. And experiments showed that this method could provide roughness parameters acceptable for meteorological models. Jeyachandran et al. defined grid cells ranging in size from 25 to $250 \mathrm{~m}$ for correlation analysis between SAR data and urban roughness but did not consider aerodynamic roughness in heterogeneous urban areas is highly related to the roughness elements in the upwind area and the scale and orientation sensitivity analysis is indispensable.

Aimed at addressing these limitations, this paper proposed an aerodynamic roughness estimation methodology from SAR data based on a precise scale and orientation analysis, where ground truth aerodynamic roughness values were calculated using meteorological tower data. First, the scale and orientation characteristics of backscattering of roughness elements in urban areas were thoroughly analyzed. Then, the optimal dimension of the upwind sector for aerodynamic roughness elements calculation was determined through a correlation analysis of 22 scenes of ALOS PALSAR data obtained from 2006 to 2011 and the wind gradient data acquired by the Beijing meteorological tower. Finally a quantitative relationship between SAR backscattering and aerodynamic roughness was set up to map the spatial and temporal aerodynamic roughness length of Beijing city from ALOS PALSAR and COSMO-SkyMed data. This paper is organized as follows. In Section 2, we introduce the study area, the SAR data, and the wind gradient data acquired from the Beijing meteorological tower. Then in Section 3, the principles and the proposed methodology for aerodynamic roughness estimation from SAR data are introduced. Experimental results and a discussion are presented in Section 4, and our conclusions are given in Section 5.

\section{Study Area and Experimental Data}

2.1. Study Area. Beijing city is the capital of China and one of the main megacities in the world. Since the reform and open policy was implemented in China, land use and land cover of Beijing city have changed dramatically due to rapid social and economic development. Buildings have become increasingly taller, and the spatial distribution of infrastructures in Beijing city becomes more and more divergent. These changes have dramatically altered the surface roughness and thus induced an obvious change in the urban boundary layer dynamics, such as changes in wind and temperature, which contributes to the deterioration in the air quality and frequent meteorological disasters in Beijing. The $325 \mathrm{~m}$ high Beijing meteorological tower has provided a powerful tool for meteorological and climate studies in Beijing. In this paper, wind gradient data observed by the meteorological tower was used to calculate the ground truth aerodynamic roughness. Figure 1(a) shows the Gaofen image of Beijing city on 12 


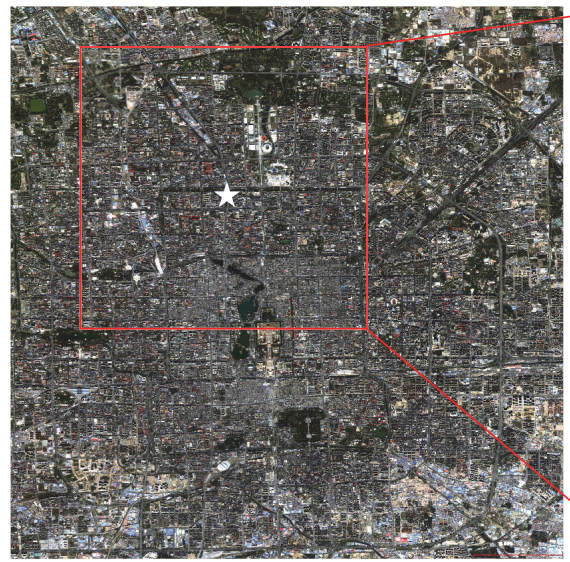

(a) The study area in the Gaofen image

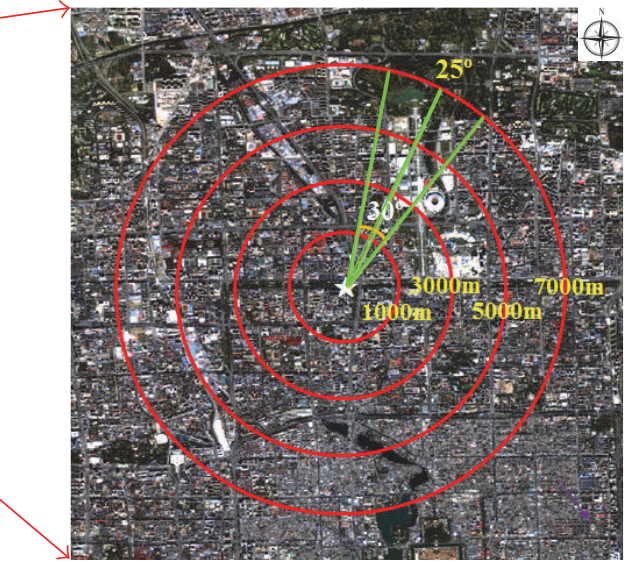

(b) The area around the Beijing meteorological tower

Figure 1: The study area of Beijing city. (a) shows the Gaofen image of Beijing city (8 m resolution) on 12 October 2015; (b) shows the area around the Beijing meteorological tower $(14 \mathrm{~km} \times 14 \mathrm{~km})$, where the white star represents the position of the meteorological tower, the red circles illustrate various dimension settings of the upwind sector, and the green lines intersecting with the red circles represent the upwind sectors with the opening angle of $30^{\circ}$, the central angle of $25^{\circ}$, and the various radii of $1000 \mathrm{~m}, 3000 \mathrm{~m}, 5000 \mathrm{~m}$, and $7000 \mathrm{~m}$.

October 2015, and (b) shows the area around the Beijing meteorological tower $(14 \mathrm{~km} \times 14 \mathrm{~km})$ which is used for the correlation and quantitative relation analysis.

2.2. Wind Gradient Data. In Figure 1 the white star illustrates the position of the Beijing meteorological tower, where its longitude is $116^{\circ} 22^{\prime} \mathrm{E}$ and latitude is $39^{\circ} 58^{\prime} \mathrm{N}$. This tower has made great contributions to meteorological studies of Beijing city. At the early stage of its establishment, this meteorological tower was in the suburb of Beijing city, and most targets around this tower were crops or bare soil. With the development of Beijing city, the uniform surface around the tower has changed into a very complicated and heterogeneous one. Figure 2 shows photos of the underlying surface in the northeast $\left(0-45^{\circ}\right)$ and southwest $\left(180-225^{\circ}\right)$ directions, respectively, which shows that there are great differences between the roughness elements in different directions. Yet the aerodynamic roughness value calculated using wind gradient data can only represent the aerodynamic roughness characteristics of the limited extent around the meteorological tower, and only using one value can not reveal the detailed information of the whole Beijing city due to the high spatial variations of the urban targets.

Figure 3 shows photos of the Beijing meteorological tower, which includes 15 observation layers with height, respectively, at $9 \mathrm{~m}, 15 \mathrm{~m}, 32 \mathrm{~m}, 47 \mathrm{~m}, 65 \mathrm{~m}, 80 \mathrm{~m}, 103 \mathrm{~m}$, $120 \mathrm{~m}, 140 \mathrm{~m}, 160 \mathrm{~m}, 180 \mathrm{~m}, 200 \mathrm{~m}, 240 \mathrm{~m}, 280 \mathrm{~m}$, and $320 \mathrm{~m}$. At each layer, the anemometer, anemoscope, thermometer, and hygrometer are mounted. The sampling time interval for meteorological data is 20 seconds, and the observed parameters include wind velocity and direction, humidity, and temperature. In this paper, multilayer wind data five days before and after the SAR imaging date (totally 106 days for ALOS PALSAR and 220 days for COSMO-SkyMed) were acquired and used for the ground truth aerodynamic roughness calculation.
2.3. SAR Data. In this paper, a total of 22 scenes of Single Look Complex (SLC) ALOS PALSAR data collected from 2006 to 2011 were used in our analysis and modeling. All of the ALOS PALSAR data are in the L-band, StripMap mode, and the incidence angle is $38.7^{\circ}$. Among them, 10 scenes are single polarization mode $(\mathrm{HH})$, and the other 12 scenes are dual polarization mode ( $\mathrm{HH}$ and $\mathrm{HV}$ ). The detailed parameters of the ALOS PALSAR data are shown in Table 1.

Besides ALOS PALSAR data, a total of 22 scenes of COSMO-SkyMed data from 2009 through 2011 were jointly used for the temporal variation analysis of the aerodynamic roughness of Beijing city. All of the COSMO-SkyMed data are in the $\mathrm{X}$ band, $\mathrm{HH}$ polarization, StripMap mode, and the incidence angle is $18.3^{\circ}$. The detailed parameters of the COSMOSkyMed data are shown in Table 2.

\section{Principles and Methodology}

3.1. Basic Principles. Radar backscattering received by SAR sensor is determined by the geometric structure, dielectric characteristics of targets, as well as the sensor parameters, and the spatial relations between the SAR sensor and targets. And there are great differences between the backscattering mechanisms of various land use types. For smooth surfaces, such as water or smooth roads, specular reflection is the dominant scattering. For rough surfaces, such as trees or crops, volume scattering is the dominant scattering. And for very rough surfaces, such as built-up areas or other artificial targets, dihedral scattering is the dominant scattering. Besides, the backscattering characteristics of urban areas highly rely on the spatial scale. On low or middle resolution SAR image, the backscattering coefficient reflects the general characteristics of land use types, while, on high resolution SAR image, more detailed information can be revealed. Jeyachandran et al. used SIR-C data and analyzed the backscattering coefficients of typical targets in urban areas in 2009, and their results 


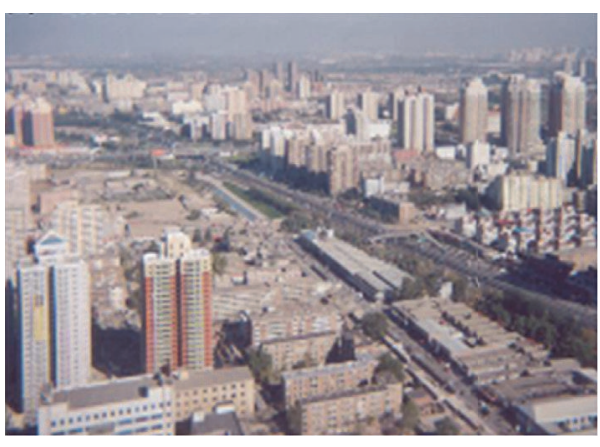

(a) Photo in the orientation of $0-45^{\circ}$

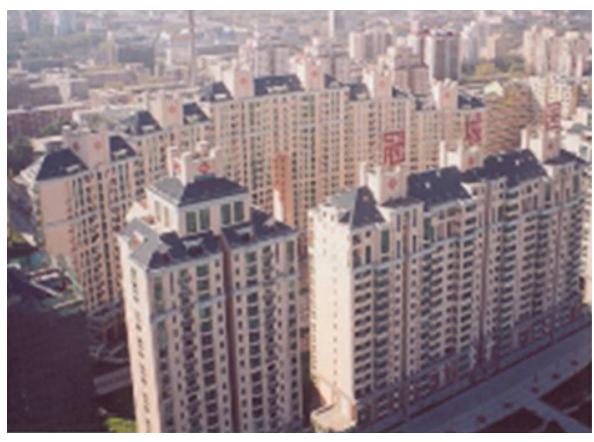

(b) Photo in the orientation of $180-225^{\circ}$

FIGURE 2: Photos of the Beijing meteorological tower in various orientations, where (a) represents the northeast direction and (b) represents the southwest direction.

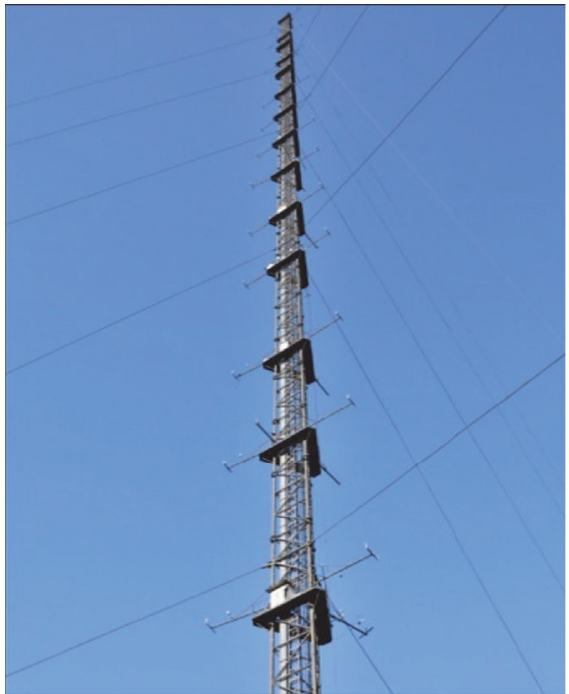

(a) The Beijing meteorological tower

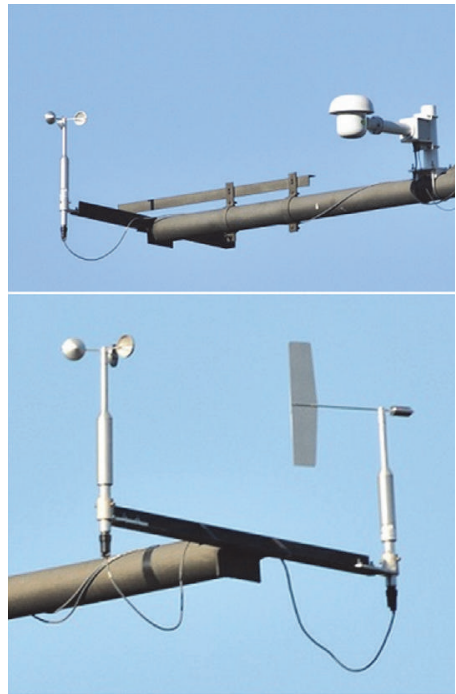

(b) The wind measurement sensors

FIgURE 3: Photos of the Beijing meteorological tower and the sensors used for obtaining wind measurements.

showed that the backscattering coefficient increases with the roughness of targets [15].

We extracted backscattering coefficients of typical land use types in Beijing city from ALOS PALSAR data and COSMO-SkyMed data, including residential areas, central business district, high-rise building area, green land, road, and water. And the high resolution optical data and field surveys were used for validation. Table 3 illustrates the results extracted from ALOS PALSAR data. From Table 3 we can see the mean values of the six land use types are obviously different, but the minimum and maximum values of some land use types are approaching. In particular the maximum values of the first three classes, that is, residential area, central business district, and high-rise building area, are the same. This is because dihedral scattering, trihedral scattering, and multiple bounce scattering between adjacent urban targets make the backscattered echoes superimposed together and cause saturation in some cases. This is easy to happen for tall building areas, so the maximum backscattering values of the first 3 classes are the same, which means the backscattered echoes are saturated. Therefore we think the mean value of the backscattering coefficient can better represent the characteristics of land use types in urban areas and reveal their difference. The average backscattering coefficient of high-rise building areas is the largest, with a mean value of $0.07 \mathrm{~dB}$. The backscattering coefficient of the central business district has the second largest value, with a mean of $-0.53 \mathrm{~dB}$, and the backscattering coefficient of an ordinary residential area has the third largest value, with a mean of $-6.23 \mathrm{~dB}$. There are obvious differences among the average backscattering coefficients of various built-up areas, and they are all much higher than the backscattering coefficient of relatively smooth surfaces such as roads and waters.

Experiments based on COSMO-SkyMed showed that the absolute value of backscattering coefficient was a little different to that from ALOS PALSAR, yet the rule of the backscattering coefficient difference between various land use types was the same. Our results also were compared with that of 
TABLE 1: Detailed parameters of the ALOS PALSAR data used in this paper.

\begin{tabular}{lcccc}
\hline Number & $\begin{array}{c}\text { Acquisition } \\
\text { date }\end{array}$ & $\begin{array}{c}\text { Polarization } \\
\text { mode }\end{array}$ & $\begin{array}{c}\text { Range pixel } \\
\text { spacing }(\mathrm{m})\end{array}$ & $\begin{array}{c}\text { Azimuth pixel } \\
\text { spacing }(\mathrm{m})\end{array}$ \\
\hline 1 & $6 / 23 / 2006$ & $\mathrm{HH}$ & 4.68 & 3.44 \\
2 & $1 / 17 / 2007$ & $\mathrm{HH}$ & 4.68 & 3.07 \\
3 & $6 / 21 / 2007$ & $\mathrm{HH} / \mathrm{HV}$ & 9.36 & 3.06 \\
4 & $2 / 6 / 2008$ & $\mathrm{HH}$ & 4.68 & 3.06 \\
5 & $7 / 22 / 2008$ & $\mathrm{HH} / \mathrm{HV}$ & 9.36 & 3.08 \\
6 & $2 / 8 / 2009$ & $\mathrm{HH}$ & 4.68 & 3.07 \\
7 & $8 / 11 / 2009$ & $\mathrm{HH} / \mathrm{HV}$ & 9.36 & 3.06 \\
8 & $1 / 25 / 2010$ & $\mathrm{HH}$ & 4.68 & 3.08 \\
9 & $3 / 12 / 2010$ & $\mathrm{HH}$ & 4.68 & 3.08 \\
10 & $3 / 29 / 2010$ & $\mathrm{HH}$ & 4.68 & 3.06 \\
11 & $4 / 27 / 2010$ & $\mathrm{HH}$ & 4.68 & 3.06 \\
12 & $5 / 14 / 2010$ & $\mathrm{HH} / \mathrm{HV}$ & 9.36 & 3.05 \\
13 & $6 / 12 / 2010$ & $\mathrm{HH} / \mathrm{HV}$ & 9.36 & 3.06 \\
14 & $6 / 29 / 2010$ & $\mathrm{HH} / \mathrm{HV}$ & 9.36 & 3.07 \\
15 & $7 / 28 / 2010$ & $\mathrm{HH} / \mathrm{HV}$ & 9.36 & 3.07 \\
16 & $8 / 14 / 2010$ & $\mathrm{HH} / \mathrm{HV}$ & 9.36 & 3.06 \\
17 & $9 / 29 / 2010$ & $\mathrm{HH} / \mathrm{HV}$ & 9.36 & 3.07 \\
18 & $10 / 28 / 2010$ & $\mathrm{HH} / \mathrm{HV}$ & 9.36 & 3.07 \\
19 & $11 / 14 / 2010$ & $\mathrm{HH} / \mathrm{HV}$ & 9.36 & 3.08 \\
20 & $12 / 13 / 2010$ & $\mathrm{HH} / \mathrm{HV}$ & 9.36 & 3.08 \\
21 & $12 / 30 / 2010$ & $\mathrm{HH}$ & 4.68 & 3.06 \\
22 & $3 / 15 / 2011$ & $\mathrm{HH}$ & 4.68 & 3.08 \\
\hline
\end{tabular}

Jeyachandran et al., which showed good accordance between them. That is to say, the average backscattering coefficients of SAR data can reveal the difference of various land use types in built-up areas. Thus, we think SAR data has great potentials for being used in aerodynamic roughness length retrieval because both the backscattering and the aerodynamic roughness are closely related to the geometric structures of roughness elements presented in a given land surface.

3.2. Aerodynamic Roughness Length Estimation Methodology from ALOS PALSAR Data. The procedures for aerodynamic roughness length estimation from SAR data are illustrated in Figure 4, which mainly include ALOS PALSAR data processing and backscattering analysis, ground truth aerodynamic roughness length calculation using the wind gradient data, correlation analysis between the backscattering coefficient and the ground truth aerodynamic roughness length for different upwind sectors of various dimensions, and ultimately establishing of a quantitative relationship and the aerodynamic roughness length mapping. The details are described as follows.

(1) Processing ALOS PALSAR data: the multilook processing was first applied to the SLC ALOS PALSAR data to produce intensity images with an improved radiometric resolution and reduced speckle noises through averaging along the range and azimuth direction. When calculating the
TABLE 2: Detailed parameters of the COSMO-SkyMed data used in this paper.

\begin{tabular}{lcccc}
\hline Number & $\begin{array}{c}\text { Acquisition } \\
\text { date }\end{array}$ & $\begin{array}{c}\text { Polarization } \\
\text { mode }\end{array}$ & $\begin{array}{c}\text { Range pixel } \\
\text { spacing }(\mathrm{m})\end{array}$ & $\begin{array}{c}\text { Azimuth pixel } \\
\text { spacing }(\mathrm{m})\end{array}$ \\
\hline 1 & $1 / 4 / 2009$ & $\mathrm{HH}$ & 0.77 & 2.27 \\
2 & $3 / 17 / 2009$ & $\mathrm{HH}$ & 0.77 & 2.27 \\
3 & $5 / 20 / 2009$ & $\mathrm{HH}$ & 0.77 & 2.27 \\
4 & $6 / 13 / 2009$ & $\mathrm{HH}$ & 0.77 & 2.27 \\
5 & $7 / 31 / 2009$ & $\mathrm{HH}$ & 0.77 & 2.27 \\
6 & $10 / 19 / 2009$ & $\mathrm{HH}$ & 0.77 & 2.27 \\
7 & $11 / 20 / 2009$ & $\mathrm{HH}$ & 0.77 & 2.27 \\
8 & $12 / 6 / 2009$ & $\mathrm{HH}$ & 0.77 & 2.27 \\
9 & $1 / 23 / 2010$ & $\mathrm{HH}$ & 0.77 & 2.27 \\
10 & $2 / 24 / 2010$ & $\mathrm{HH}$ & 0.77 & 2.27 \\
11 & $3 / 12 / 2010$ & $\mathrm{HH}$ & 0.77 & 2.27 \\
12 & $5 / 31 / 2010$ & $\mathrm{HH}$ & 0.77 & 2.27 \\
13 & $7 / 18 / 2010$ & $\mathrm{HH}$ & 0.77 & 2.27 \\
14 & $9 / 4 / 2010$ & $\mathrm{HH}$ & 0.77 & 2.27 \\
15 & $10 / 6 / 2010$ & $\mathrm{HH}$ & 0.77 & 2.27 \\
16 & $11 / 7 / 2010$ & $\mathrm{HH}$ & 0.77 & 2.27 \\
17 & $12 / 9 / 2010$ & $\mathrm{HH}$ & 0.77 & 2.27 \\
18 & $5 / 18 / 2011$ & $\mathrm{HH}$ & 0.77 & 2.27 \\
19 & $5 / 26 / 2011$ & $\mathrm{HH}$ & 0.77 & 2.27 \\
20 & $6 / 19 / 2011$ & $\mathrm{HH}$ & 0.77 & 2.27 \\
21 & $7 / 29 / 2011$ & $\mathrm{HH}$ & 0.77 & 2.27 \\
22 & $8 / 14 / 2011$ & $\mathrm{HH}$ & 0.77 & 2.27 \\
\hline
\end{tabular}

TABLE 3: Backscattering coefficients of various land use types extracted from ALOS PALSAR data.

\begin{tabular}{lccc}
\hline Land use type & Minimum/dB & Maximum/dB & Mean/dB \\
\hline Residential area & -15.04 & 6.99 & -6.23 \\
Central business district & -13.99 & 6.99 & -0.53 \\
High-rise building area & -15.26 & 6.99 & 0.07 \\
Green land & -16.92 & -3.07 & -11.09 \\
Road & -15.97 & 3.61 & -11.16 \\
Water & -17.41 & -9.09 & -12.95 \\
\hline
\end{tabular}

number of looks for multilook processing, the range resolution is firstly calculated using pixel spacing in slant range/sin (incidence angle). For the single polarized data, taking the image acquired on 23 June 2006 as an example, the range resolution is equal to $4.68 / \mathrm{sin}(38.7 / 180 * 3.14)=7.49 \mathrm{~m}$. The number of looks in range direction is set to be 1 , and the azimuth resolution should be the same with the range direction to obtain a square pixel size, that is, $7.49 / 3.44 \approx 2$. The number of looks can be calculated in the similar way and then the multilook operation can be performed for the dual polarization mode data. So the multilook factors in range and azimuth for the single polarization images are one and two, respectively, and the multilook factors in range and azimuth for the dual polarization images are one and five, respectively. 


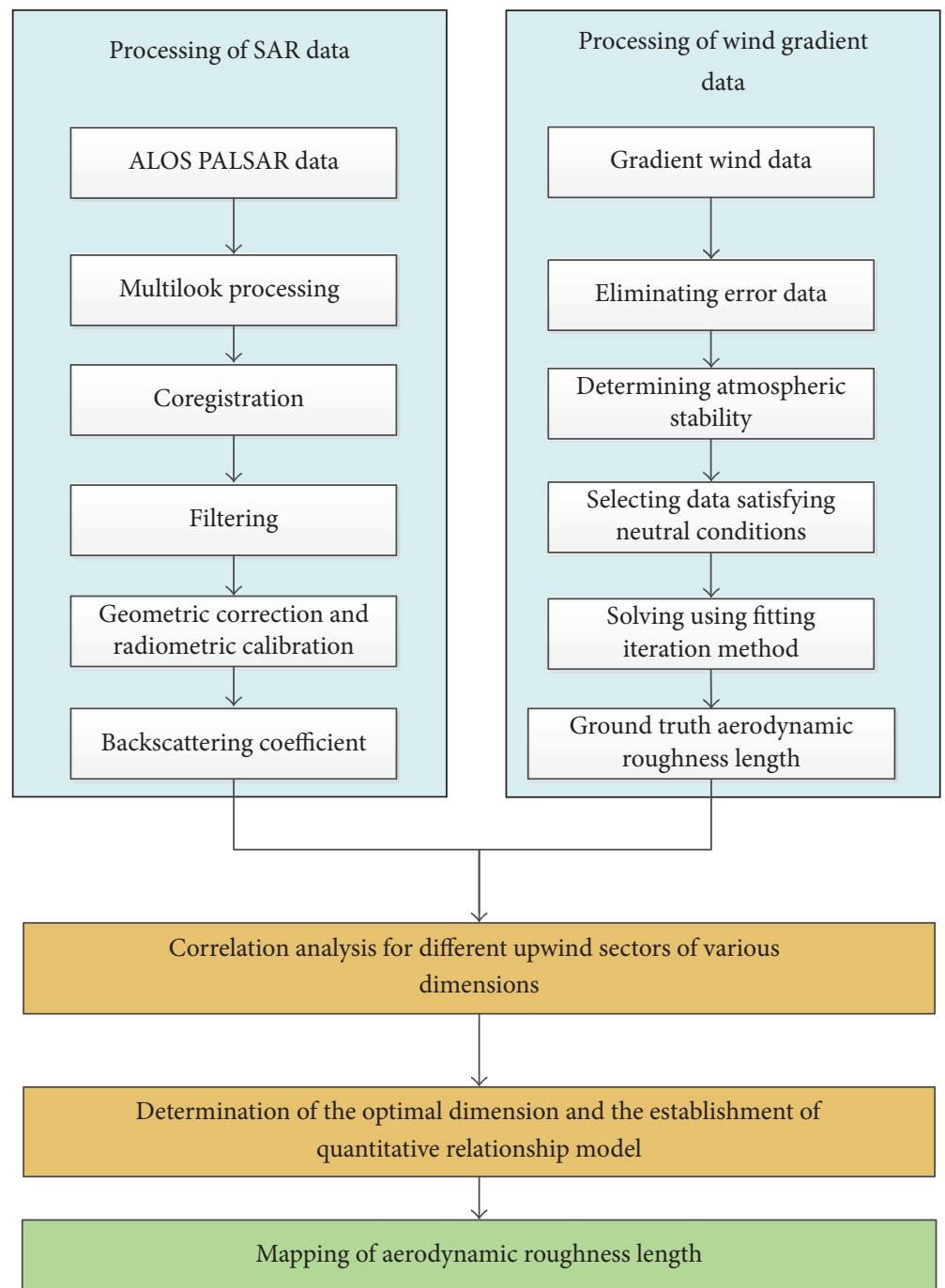

FIGURE 4: A flowchart of aerodynamic roughness length estimation from ALOS PALSAR data.

Then, the 22 scenes of ALOS PALSAR images were coregistered, which required spatial registration and resampling (in cases where the pixel sizes differed) to correct relative translational shift, rotation, and scale differences. Then the De Grandi filtering was performed to these 22 scenes of multitemporal ALOS PALSAR images to exploit the spacevarying temporal correlation of speckles between the images to further suppress the system-inherent multiplicative noise presented in the SAR data [16]. Finally, a geometric correction and radiometric calibration were applied to the ALOS PALSAR images to make a meaningful intercomparison of the backscattering coefficient determined at different dates. In this paper we did not use the HV channel data, and the backscattering coefficient of $\mathrm{HH}$ polarization was used for all analysis.

(2) Processing of the wind gradient data observed by the meteorological tower: first, obvious error data was eliminated, and then the Richardson Number was used to determine atmosphere stability. Then gradient wind data classified as arising from neutral conditions were adopted to calculate the ground truth aerodynamic roughness length at different orientations using fitting iteration method [17].

According to Monin-Obukhov similarity theory, a logarithmic relationship exists between horizontal wind speeds and measurement height; that is,

$$
u(z)=\frac{u_{*}}{k} \ln \left(\frac{z-d_{0}}{z_{0}}\right),
$$

where $u_{*}$ is the friction velocity determined from the wind profile measurement $(\mathrm{m} / \mathrm{s}), k$ is von Karman's constant (usually set to 0.4$), u(z)$ is the mean wind speed $(\mathrm{m} / \mathrm{s})$ at height $z(\mathrm{~m}), d_{0}$ is the zero-plane displacement $(\mathrm{m})$, and $z_{0}$ is the roughness length $(\mathrm{m})$.

Equation (1) can be rewritten as

$$
u(z)=\frac{u_{*}}{k}\left(\ln \left(z-d_{0}\right)-\ln \left(z_{0}\right)\right),
$$

where there is usually $d_{0}=c z_{0}$, and $c$ takes $5 \sim 7$.

Thus $z_{0}$ and $d_{0}$ can be calculated through two steps according to (2) using a fitting iteration method [18]. Firstly, 
supposing various values for $d_{0}$, a linear regression analysis was performed between $u(z)$ and $\ln \left(z-d_{0}\right)$, and the value of $d_{0}$ was taken as optimal when the maximum correlation between $\ln \left(z-d_{0}\right)$ and $u(z)$ was achieved. Then once the value of $d_{0}$ was decided, $u_{*}$ were calculated according to the slope of the linear regression line described as $u_{*} / k$, and $z_{0}$ were derived from the intercept of the linear regression line described as $\left(u_{*} / k\right) \ln z_{0}$, respectively. In this paper, the observed wind data at meteorological tower heights of $32 \mathrm{~m}$, $47 \mathrm{~m}, 65 \mathrm{~m}$, and $80 \mathrm{~m}$ were used for calculating the ground truth roughness length because they could more easily satisfy the logarithmic relationship [17].

(3) The aerodynamic roughness is related to the topology of the roughness elements in the upwind sector, which can be described by three parameters: the central angle $\theta$, the radius $r$, and the opening angle $\alpha[13,19]$. The dimension of the upwind sector also represents the effective range of the upwind, meaning out of which the local flow effects can be neglected. Zhu et al. suggested that the dimension of the upwind sector should be determined according to the height of the mounted anemometer and suggested a radius that is 100 times greater than this height, with an opening angle of $30^{\circ}$ [19]. Bechtel et al. suggested that the dimension of the upwind sector should be determined according to the height of roughness elements and suggested a radius of the upwind sector that is 20 times greater than the average height of the roughness elements [13].

In this paper, upwind sectors with various dimensions and orientations were defined to perform a backscattering analysis and a correlation analysis with ground truth aerodynamic roughness lengths. The north direction was defined as the $0^{\circ}$ orientation and the clockwise direction as the positive direction (see Figure 1(b)). Thirteen upwind sector radii were defined, in the range $1000 \mathrm{~m}$ to $7000 \mathrm{~m}$, with steps of $500 \mathrm{~m}$, and three upwind opening angles were defined: $30^{\circ}, 45^{\circ}$, and $60^{\circ}$. Upwind sectors of the Beijing meteorological tower in the $25^{\circ}$ orientation with an opening angle of $30^{\circ}$ and radii of 1000 m, 3000 m, 5000 m, and 7000 m are illustrated in Figure 1(b). In our methodology, an upwind sector with specific dimensions was analyzed within the whole test image in $5^{\circ}$ intervals, where the mean value of backscattering coefficient within the predefined upwind sector (illustrated using the green lines intersecting with the red circles in Figure 1(b)) was extracted and its correlation with the ground truth roughness length in the same direction was analyzed.

(4) The optimal dimension of the upwind sector was determined when the correlation between the backscattering coefficient within the sector and the ground truth roughness length in the same direction was at a maximum. Then the quantitative relationship model was set up between them, and the model was then used to map the aerodynamic roughness length in Beijing city using SAR data.

\section{Results and Discussions}

4.1. Backscattering Coefficient Analysis of the SAR Data. The backscattering coefficient within each upwind sector of varying dimensions and orientation, where the Beijing meteorological tower was taken as the central point, was analyzed.
Figure 5 gives the results extracted from the ALOS PALSAR data on 21 June 2007, where we show sectors with a radius of $4500 \mathrm{~m}$, opening angles of $30^{\circ}, 45^{\circ}$, and $60^{\circ}$, respectively, and the orientation interval of the central angle of the upwind sector is $5^{\circ}$. Figure 5(a) is the ALOS PALSAR image on 21 June 2007, while Figures 5(b)-5(d) show the backscattering coefficient within the predefined upwind sector with opening angles of $30^{\circ}, 45^{\circ}$, and $60^{\circ}$, respectively.

From Figure 5, it can be seen that there are great variations in the backscattering coefficient for various orientations of the Beijing meteorological tower. According to Figures 5(b), 5(c), and 5(d), the backscattering coefficient in the southwest (with an orientation of $180-270^{\circ}$ ) is higher because there are more tall and densely distributed buildings in this direction, whereas the backscattering coefficient in the northeast $(0-$ $90^{\circ}$ ) is lower because there are many green vegetation areas, and the buildings in this direction are sparsely distributed, as seen in Figure 5(a). Moreover, the backscattering coefficient extracted from the upwind sectors with an opening angle of $30^{\circ}$ reveals more detailed information of the backscattering characteristics of the underlying surface at various orientations through comparing Figures 5(b), 5(c), and 5(d).

As mentioned above, the radius of the upwind sector also affects the aerodynamic roughness length calculation because there are different roughness elements contained in the sector for different radii. Thus the backscattering coefficients within the upwind sectors with radii changing from $1000 \mathrm{~m}$ to $7000 \mathrm{~m}$, in steps of $500 \mathrm{~m}$, were extracted and analyzed, where we took the Beijing meteorological tower as the center. Our results show that the backscattering coefficients extracted from various upwind sectors randomly change with radius because the urban areas are highly heterogeneous and the underlying roughness elements differ greatly when the radius is different. Thus in order to determine the optimal dimension of the upwind sector for the aerodynamic roughness calculation, the wind gradient data measured by the meteorological tower is needed for further analysis.

4.2. The Characteristics of the Aerodynamic Roughness Length Calculated Using the Wind Gradient Data. For the 106 day wind gradient data, experiments were firstly performed to evaluate whether they satisfied the neutral conditions or not according to the Richardson Number. And 86 groups of wind data that satisfied the neutral conditions requirement were used in the aerodynamic roughness length calculation via the fitting iteration method. Figure 6 illustrates the aerodynamic roughness length in each orientation, where the Beijing meteorological tower was taken as the center. According to Figure 6 , the aerodynamic roughness length calculated using the wind gradient data ranged from $0 \mathrm{~m}$ to $6 \mathrm{~m}$, where most were between $1 \mathrm{~m}$ and $3 \mathrm{~m}$. It can be seen in Figure 6 that the value of $z_{0}$ to the southwest $\left(180-240^{\circ}\right)$ of the Beijing meteorological tower is larger because there are many buildings higher than $50 \mathrm{~m}$ in this direction, which is similar to the conclusions of $\mathrm{Li}$ et al. [17]. It can be seen in Figure 6 that the prevailing wind direction in Beijing city is from the northwest, because there are more data arising from $330-360^{\circ}$ directions. 


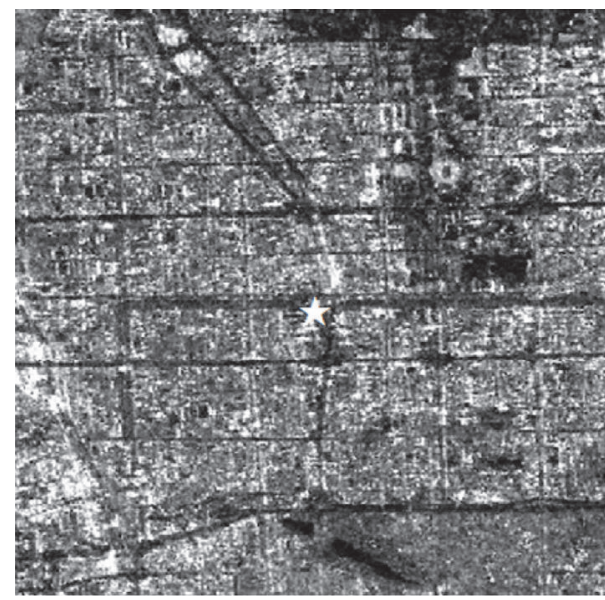

(a)

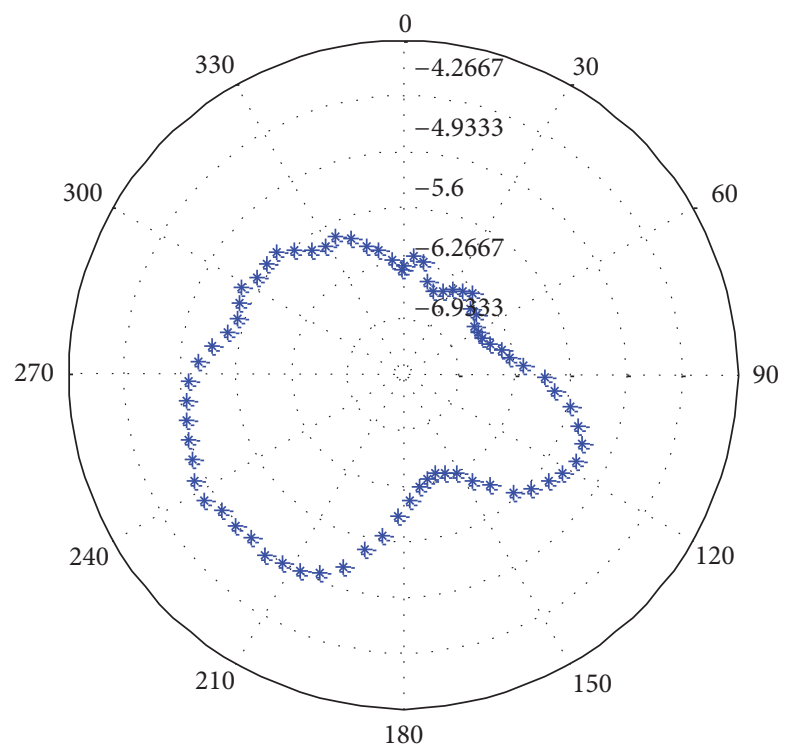

(c)

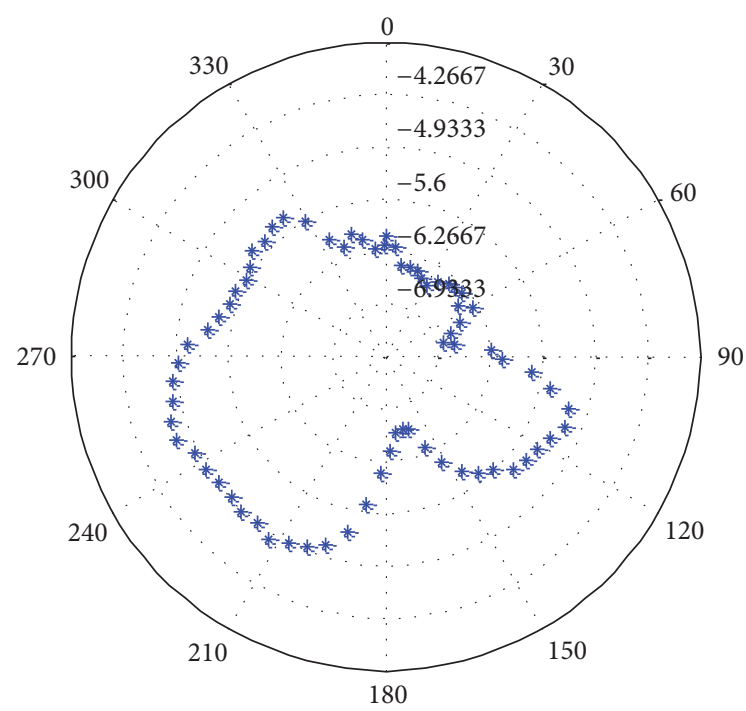

(b)

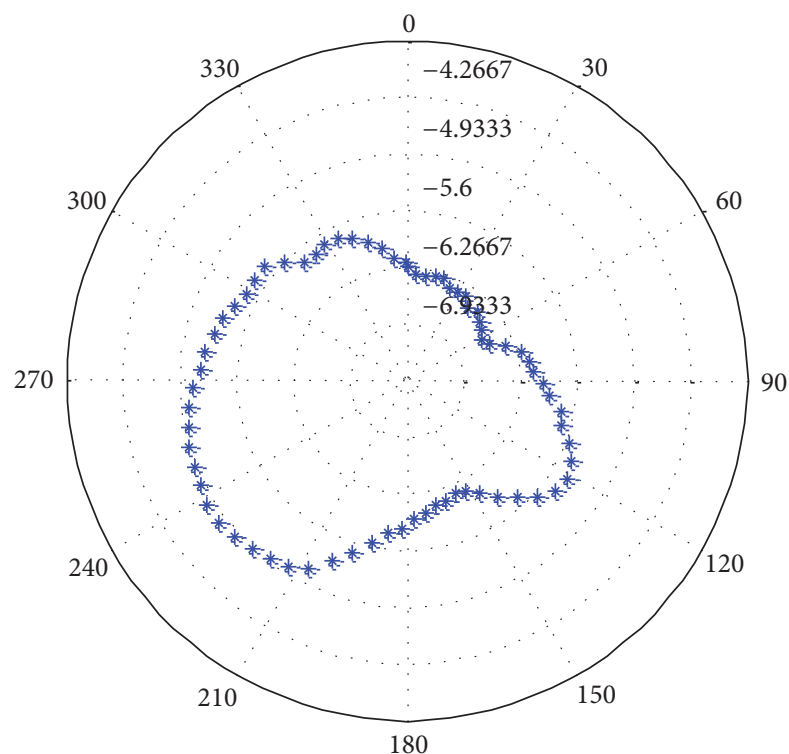

(d)

FIGURE 5: The backscattering coefficient extracted from various upwind sectors for the Beijing meteorological tower. (a) is the ALOS PALSAR image on 21 June 2007, and (b)-(d) show the backscattering coefficient within the predefined upwind sector with a radius of $4500 \mathrm{~m}$, opening angles of $30^{\circ}, 45^{\circ}$, and $60^{\circ}$, respectively.

After calculation of $z_{0}$ from wind gradient data, we compared it with previous studies in the similar upwind direction. Then all the values of $z_{0}$ in the similar upwind direction calculated by us as well as those from literatures were plotted along with time. In Figure 7, our calculated value of $z_{0}$ was compared with the results of previous studies by $\mathrm{Li}$ et al. [17], $\mathrm{Hu}$ [20], Zhang and Chen [21], Gao et al. [22], and Ju [23]. $\mathrm{Hu}, \mathrm{Gao}$, and Zhang and Chen divided the range 0$360^{\circ}$ into eight subranges, and Figure 7 shows $z_{0}$ within the $315-360^{\circ}$ directions. Li divided $0-360^{\circ}$ into four sections, and Figure 7 shows $z_{0}$ in the northwest direction $\left(270-360^{\circ}\right)$. For comparison in Figure 7 we show our calculated $z_{0}$ within the $330-360^{\circ}$ direction. From Figure 7 , it can be seen that the value of $z_{0}$ calculated by us is in good accordance with other studies, except that of $\mathrm{Li}$, because the direction range considered by $\mathrm{Li}$ is much wider than ours, and the subsequent roughness elements in the various orientations are different. According to Figure 7, the aerodynamic roughness length to the northwest direction of the Beijing meteorological tower increased from 1985 to 2010, in accordance with the actual situations of Beijing city. And if a linear fitting is performed for all the values of $z_{0}$ except that of $\mathrm{Li}$ et al., the coefficient of determination is 0.76 , and the root mean squared error is $0.35 \mathrm{~m}$. 


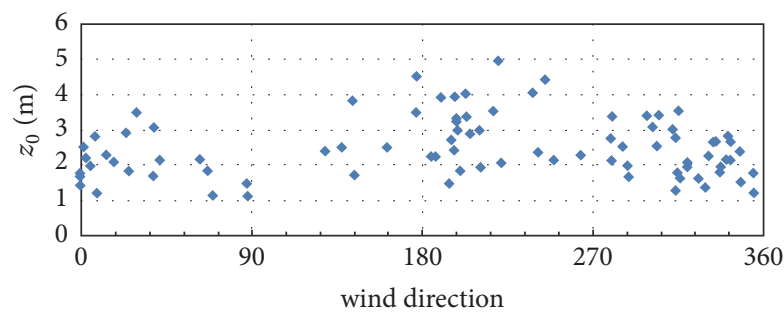

FIGURE 6: The aerodynamic roughness length calculated using wind gradient data along with the wind orientation.

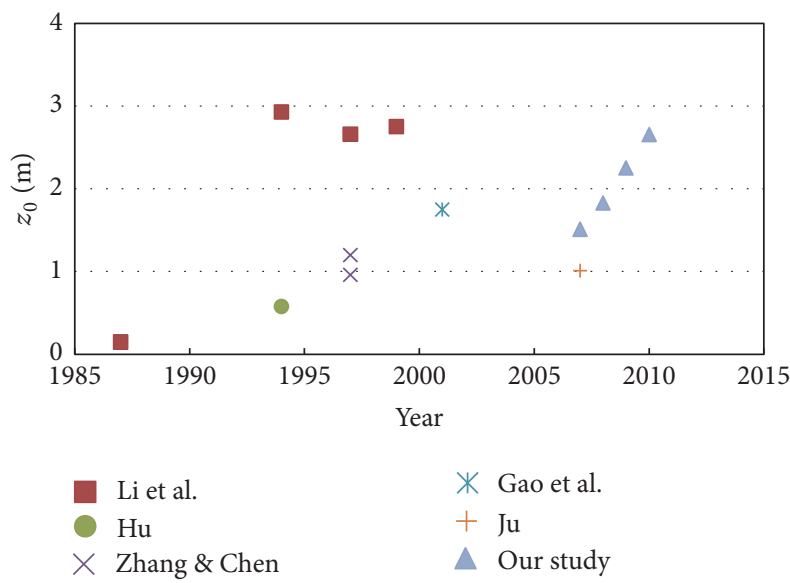

Figure 7: Comparison of $z_{0}$ calculated by various studies and its variation with time.

4.3. Correlations Analysis of SAR Backscattering and the Ground Truth Aerodynamic Roughness Length. In order to analyze the effect of the upwind sector dimension on the roughness length calculation, the following correlation analysis between the backscattering coefficient extracted from SAR data and the ground truth roughness length calculated using wind gradient data was carried out. The ground truth roughness length calculated using meteorological data was defined as $z_{0}^{i, \theta_{i}}$, where $\theta_{i}$ represents the wind direction of the valid aerodynamic roughness length value $z_{0}$ numbered as $i$ ranging from 1 to 86 . Then for the 22 scenes of ALOS PALSAR images, a series of upwind sectors $\left(\theta_{i}, r, \alpha\right)$ with different dimensions were defined according to the acquired date and wind direction of the ground truth aerodynamic roughness length value $z_{0}^{i, \theta_{i}}$, and then the backscattering coefficients $\sigma_{\theta_{i}, r, \alpha}^{i}$ within the upwind sector were extracted. Here $\theta_{i}$ represents the central angle of the sector, which corresponds to the wind direction of the $i$ th ground truth aerodynamic roughness length, $r$ represents the radius of the sector, which ranges from $1000 \mathrm{~m}$ to $7000 \mathrm{~m}$ with steps of $500 \mathrm{~m}$, and $\alpha$ is the opening angle of the sector, with values of $30^{\circ}, 45^{\circ}$, and $60^{\circ}$. The coefficient of determination is $\left(R^{2}\right)$ between the ground truth aerodynamic roughness length $z_{0}^{\theta}=\left\{z_{0}^{1, \theta_{1}}\right.$, $\left.z_{0}^{2, \theta_{2}}, \ldots, z_{0}^{i, \theta_{i}}, \ldots, z_{0}^{85, \theta_{85}}, z_{0}^{86, \theta_{86}}\right\}$ and the backscattering coefficient $\sigma_{\theta, r, \alpha}=\left\{\sigma_{\theta_{1}, r, \alpha}^{1}, \sigma_{\theta_{2}, r, \alpha}^{2}, \ldots, \sigma_{\theta_{i}, r, \alpha}^{i}, \ldots, \sigma_{\theta_{85}, r, \alpha}^{85}, \sigma_{\theta_{86}, r, \alpha}^{86}\right\}$

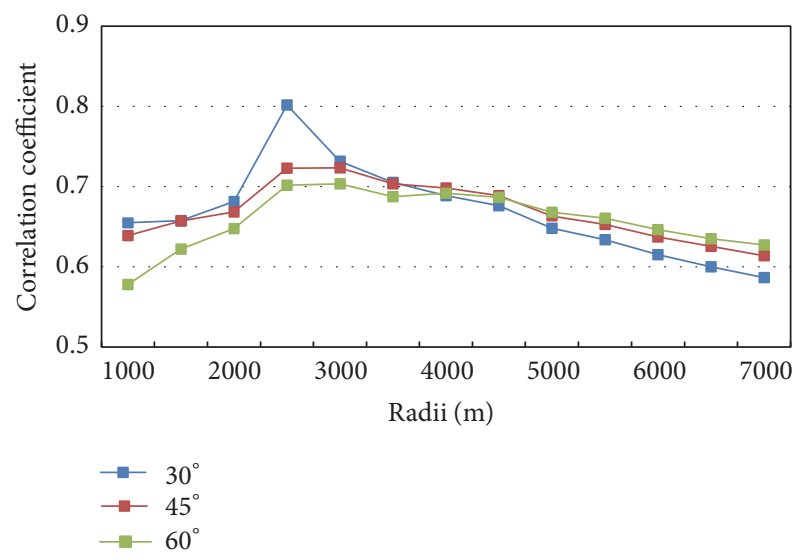

FIGURE 8: The coefficient of determination between the backscattering coefficient and the ground truth roughness length as a function of upwind sector radius for opening angles of $30^{\circ}, 45^{\circ}$, and $60^{\circ}$.

extracted from upwind sectors with certain radii and opening angles were calculated, respectively. Figure 8 illustrates the coefficient of determination between the backscattering coefficient and the ground truth $z_{0}$ for upwind sector radii ranging from $1000 \mathrm{~m}$ to $7000 \mathrm{~m}$ and opening angles of $30^{\circ}$, $45^{\circ}$, and $60^{\circ}$.

According to Figure 8, the coefficient of determination increases with an increase in sector radius when the radius is less than $2500 \mathrm{~m}$. When the sector radius is larger than $2500 \mathrm{~m}$, the coefficient of determination decreases with an increase in sector radius. When the radius is less than $3500 \mathrm{~m}$, the coefficient of determination for the $30^{\circ}$ opening angle is generally larger than the other two angles, and when the radius is larger than $3500 \mathrm{~m}$, the determination coefficient of the $60^{\circ}$ opening angle is generally larger than the other two angles. Among all the data, the coefficient of determination has a maximum of 0.802 for the $2500 \mathrm{~m}$ radius and $30^{\circ}$ opening angle, which means that the roughness elements within the upwind sector of this dimension affect the aerodynamic roughness most.

The dimension of the fetch area which can best represent the effect of the roughness elements in the upwind direction has been kept as a controversial question. In this paper we determined the optimal dimension of the upwind sector through statistical correlation analysis between the backscattering coefficient extracted from SAR data and the ground truth roughness length calculated using wind gradient data. According to our knowledge, there are still lots of works which need to be carried out before we can find the physical rule behind the statistical result, and any comparison and benchmark works are highly welcomed.

4.4. Quantitative Relationship and Aerodynamic Roughness Length Mapping. Then the total of 86 pairs of ground truth aerodynamic roughness length $z_{0}$ calculated using the wind gradient data and the corresponding backscattering coefficient extracted from the optimal upwind sectors of $2500 \mathrm{~m}$ radius and $30^{\circ}$ opening angle were randomly divided into two groups. The first group contained 58 pairs of data and was 


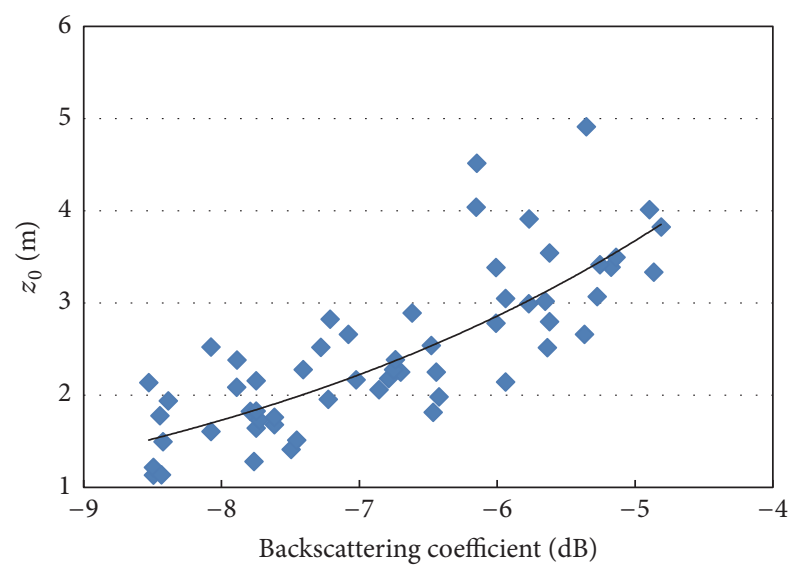

FIGURE 9: A scatter plot between the backscattering coefficient extracted from the upwind sector of radius $2500 \mathrm{~m}$ and $30^{\circ}$ opening angle in ALOS PALSAR data and the ground truth aerodynamic roughness length.

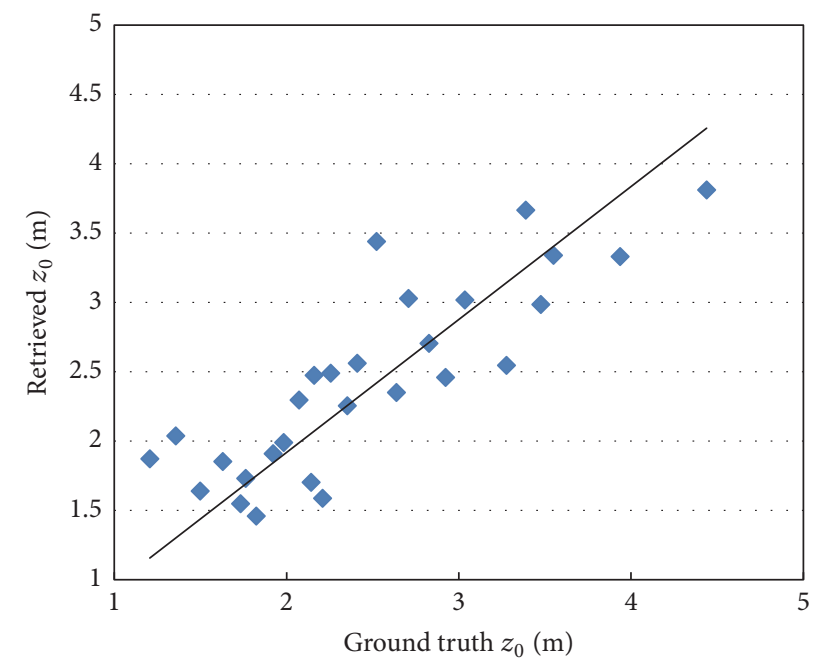

FIGURE 10: Validation of the retrieved $z_{0}$ using the remaining 28 pairs of data.

used for quantitative relationship investigation and modeling. Figure 9 shows the scatter plot between the backscattering coefficient and $z_{0}$.

According to Figure 9, the higher the backscattering coefficient is, the higher the aerodynamic roughness is. As such, an exponential formula can be used to describe the relationship between them; that is,

$$
z_{0}=12.907 e^{0.2512 \sigma_{0}} .
$$

For (3), the coefficient of determination $R^{2}=0.65$, the estimate error is $0.53 \mathrm{~m}$, and the $p$ value for no correlation hypothesis testing is 0 , showing the correlation is significant.

And the other group contained 28 pairs of data and was used for validation of (3) and the retrieved aerodynamic roughness results. Figure 10 shows the ground truth $z_{0}$ and the retrieved $z_{0}$ using ( 3 ) from ALOS PALSAR data, and the root mean square error is $0.37 \mathrm{~m}$.
For the total of 86 pairs of ground truth $z_{0}$ and the corresponding backscattering coefficient extracted from SAR data, we changed the selected 58 pairs of training data and the form of the scatter plot between $z_{0}$ and the backscattering coefficient kept unchanged, the coefficient of (3) changed, yet the exponential formula was always the best form to quantitatively describe the relationship between $z_{0}$ and the backscattering coefficient. And the exponential formula always passed the validation of the remaining data pairs. That is to say, the exponential relationship between $z_{0}$ and backscattering coefficient in the upwind sector always exists and the roughness length of other areas can be mapped using exponential formula similar to (3).

Figure 11 shows the retrieved aerodynamic roughness length in $30^{\circ}$ and $330^{\circ}$ direction using the ALOS PALSAR image on 27 April 2010. Figure 11(a) shows the ALOS PALSAR image on 27 April 2010, and Figures 11(b) and 11(c) show the corresponding retrieved aerodynamic roughness length in $30^{\circ}$ and $330^{\circ}$ direction, where the arrow represents the wind direction, that is, the central direction of the upwind sector. For Figure 11(b), an upwind sector with a central angle of $30^{\circ}$, a radius of $2500 \mathrm{~m}$, and an opening angle of $30^{\circ}$ (i.e., from the $15^{\circ}$ to $45^{\circ}$ direction) was firstly defined, the backscattering coefficient within these sectors was extracted, and the aerodynamic roughness in $30^{\circ}$ direction was retrieved using (3). The aerodynamic roughness in $330^{\circ}$ direction shown in Figure 11(c) can be mapped in the similar way.

In Figures 11(b) and 11(c), the retrieved aerodynamic roughness length falls within the range $0.7-3.4 \mathrm{~m}$, which is consistent with the ground truth data. For regions with a red color in the $z_{0}$ map, the roughness length is larger because the upwind sector contains more buildings, while for blue pixels in the $z_{0}$ map the roughness length is smaller because the upwind sector contains more water or green lands. Here take positions A and B as two examples. Position A lies near the Olympic forest park. The aerodynamic roughness length at position $\mathrm{A}$ in the $30^{\circ}$ direction is $0.86 \mathrm{~m}$ because the roughness elements contained in the upwind sector in this direction mainly include trees, grass, and water. And the aerodynamic roughness length at position $\mathrm{A}$ in the $330^{\circ}$ direction is $1.42 \mathrm{~m}$ because there are some residential buildings in the northwest direction. Position $\mathrm{B}$ lies near the commercial district. Its northeast is the Dazhongsi international square, and its northwest is Chinese Academy of Agricultural Sciences. Thus the calculated roughness length of position $\mathrm{B}$ in the $30^{\circ}$ direction is $2.77 \mathrm{~m}$ and $1.89 \mathrm{~m}$ in the $330^{\circ}$ direction, where the difference of the underlying roughness elements induces different aerodynamic roughness values. Thus the mapped roughness length from SAR data can effectively reveal detailed information of urban areas.

4.5. Temporal Variation Analysis of Aerodynamic Roughness Length Using Long Term SAR Data. According to analysis based on ALOS PALSAR data, the optimal dimension of upwind sector and the form of quantitative model can be referred and the aerodynamic roughness estimation models can be established for other SAR sensors, which is very important for long term study using multisource SAR data. 


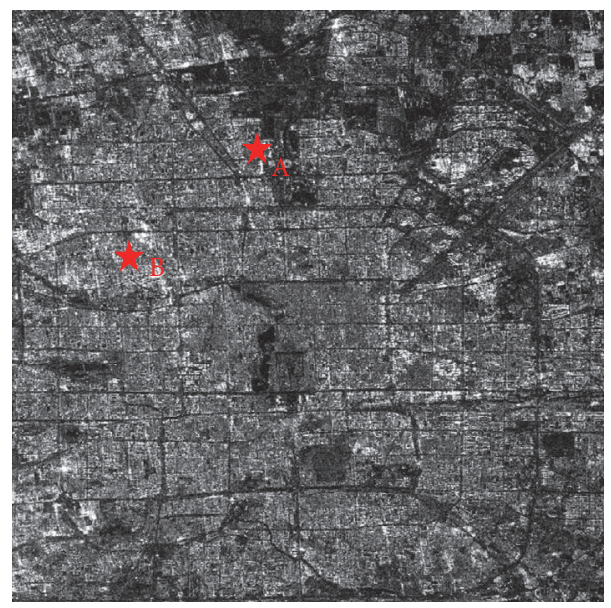

(a) ALOS PALSAR image on April 27, 2010 (the same extent with Figure 1(a))

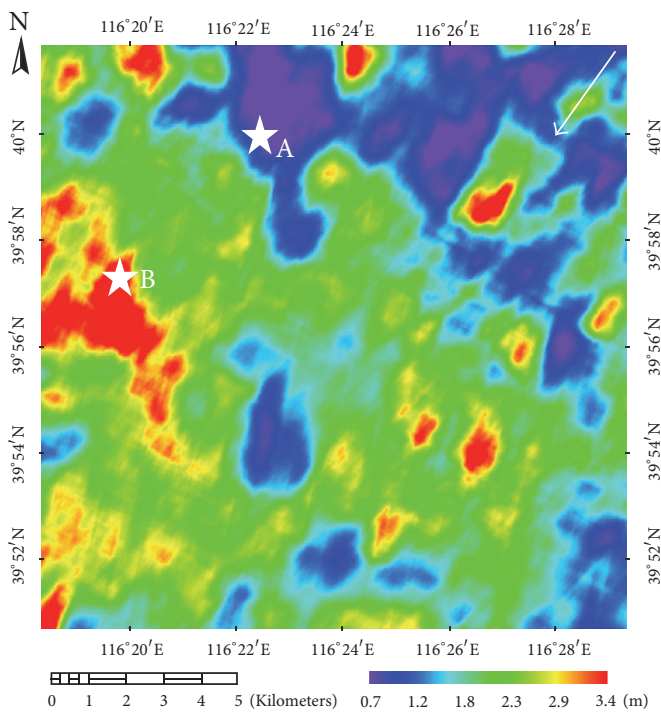

(b) The $z_{0}$ map in the $30^{\circ}$ direction (with the opening angle $\left.15-45^{\circ}\right)$

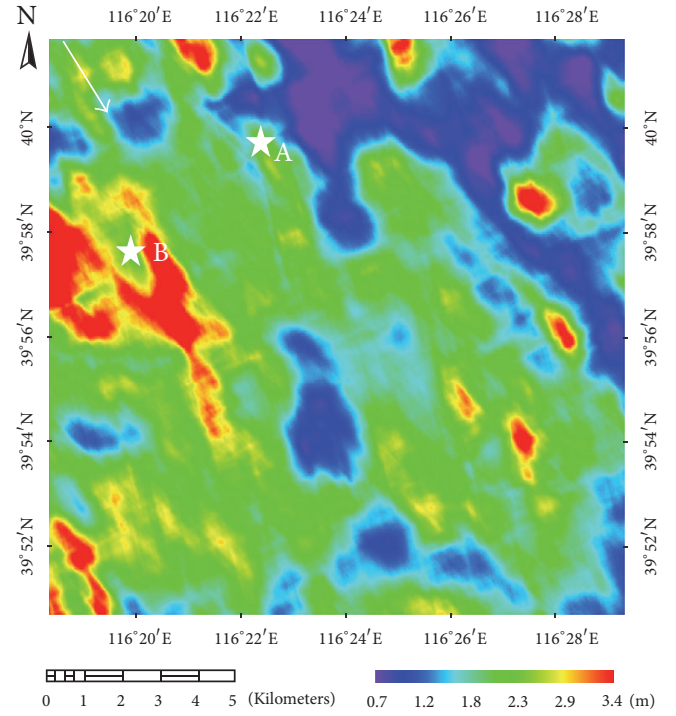

(c) The $z_{0}$ map in the of $330^{\circ}$ direction (with the opening angle $315-345^{\circ}$ )

FIgURE 11: The ALOS PALSAR image on 27 April 2010 and the retrieved aerodynamic roughness length. (a) The ALOS PALSAR image, (b) the retrieved aerodynamic roughness length in the $30^{\circ}$ direction, and (c) the retrieved aerodynamic roughness length in the $330^{\circ}$ direction. The arrow indicates the wind direction, that is, the central angle of the upwind sector. Stars A and B indicate two examples of aerodynamic roughness estimation.

Total of 22 scenes of COSMO-SkyMed data and 220 days of wind gradient data acquired from the Beijing meteorological tower were used to establish the quantitative relation between the COSMO-SkyMed and $z_{0}$. The relation model is $z_{0}=$ $17.14 e^{0.2613 \sigma_{0}}$, the determination coefficient $R^{2}=0.83$, the root mean square error is $0.18 \mathrm{~m}$, and the $p$ value for no correlation hypothesis testing is 0 , showing the correlation is significant. The correlation between the COSMO-SkyMed data and $z_{0}$ is even higher than ALOS PALSAR, which also is a good proof for the proposed methodology based on ALOS PALSAR data. Then multitemporal ALOS PALSAR and COSMO-SkyMed from 2006 to 2011 were, respectively, used to retrieve $z_{0}$ using corresponding relation model, and the temporal variation of aerodynamic roughness length of Beijing city was mapped and analyzed.

The temporal variation of the retrieved aerodynamic roughness length $z_{0}$ in the northeast of Beijing city in the $60^{\circ}$ direction (opening angle from the $45^{\circ}$ to $75^{\circ}$ direction, the radius of $2500 \mathrm{~m}$ ) is shown in Figure 12. It shows that the retrieved $z_{0}$ slowly increased with time because the buildings in the upwind sector were continuously increasing. Besides, the retrieved $z_{0}$ takes on seasonal patterns, with higher values in summer and lower values in winter, because the leaves of plants in summer increased the drag to air flow. Yet the decrease of $z_{0}$ in the winter of 2009 is not obvious, and conversely the retrieved $z_{0}$ between December of 2009 and March of 2011 is continually slowly climbing, not considering 


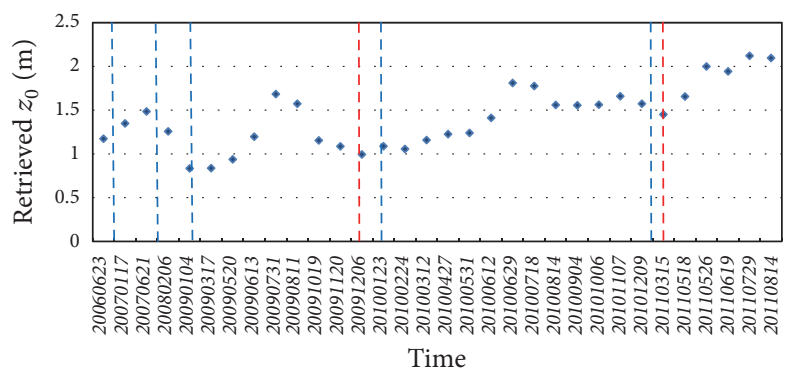

FIGURE 12: The temporal variation of $z_{0}$ in the northeast of Beijing city extracted from time series of ALOS PALSAR and COSMO-SkyMed data from 2006 to 2011. The blue lines indicate the beginning of the year, and the red lines indicate the period when buildings dramatically increased.

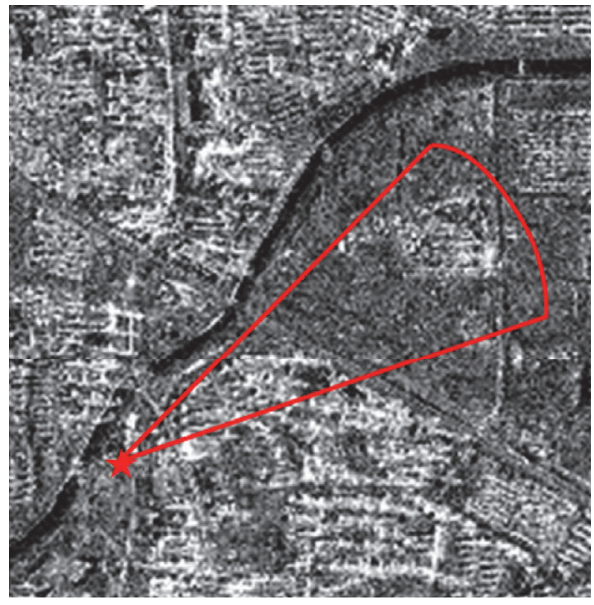

(a) June 13, 2009, COSMO-SkyMed

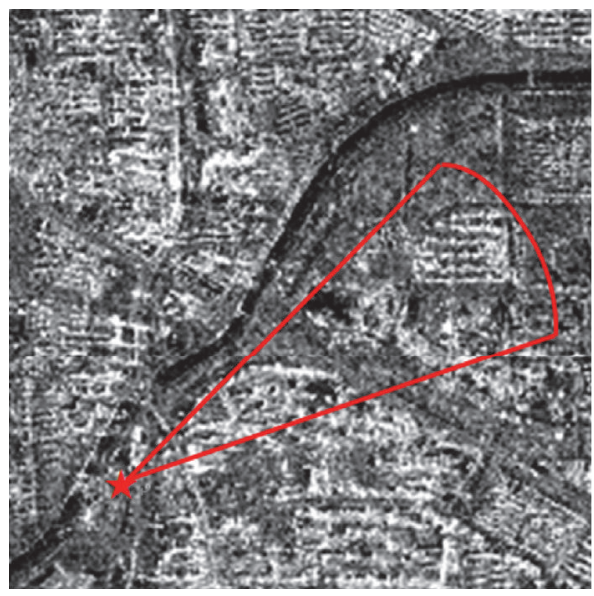

(c) December 9, 2010, COSMO-SkyMed

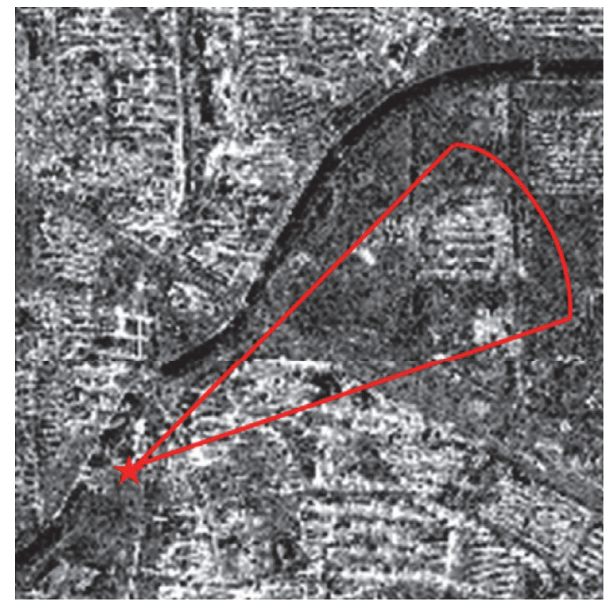

(b) December 6, 2009, COSMO-SkyMed

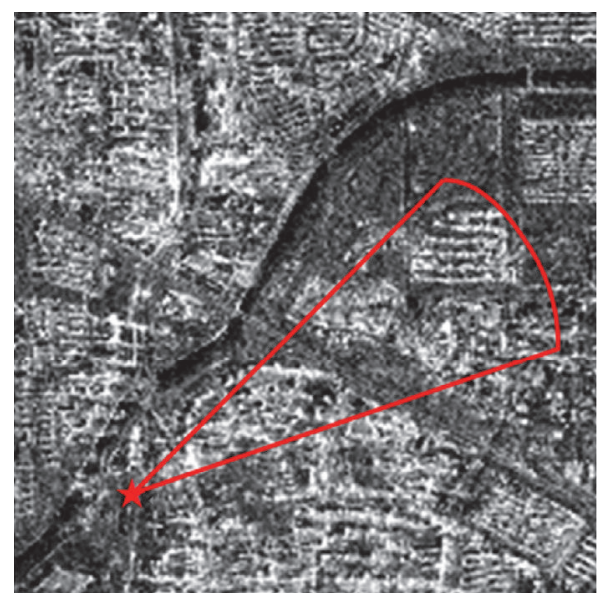

(d) March 15, 2011, ALOS PALSAR

FIGURE 13: Multitemporal SAR images of the test area. The red star indicates the position of $z_{0}$ calculation and the red lines indicate the upwind sector is in the $60^{\circ}$ direction (from the $45^{\circ}$ to $75^{\circ}$ direction, the radius of $2500 \mathrm{~m}$ ).

the seasonal effect of plants. It can be explained combining the land use change evolvement of this region (in Figure 13). Before December of 2009 this region was made up of about $30 \%$ buildings and more than $60 \%$ plants (see Figure $13(a)$ ). Since December of 2009 a lot of buildings within this region had been constructed massively and till December of 2010 buildings within this region had reached $80 \%$ (see Figures 13(b)-13(d)). Thus it can be seen that the time series of $z_{0}$ retrieved from long term SAR data can well reveal the evolvement of the land use types in urban areas. 


\section{Conclusions}

In this paper the aerodynamic roughness length estimation methodology from SAR data was introduced by using Beijing city as an example. Wind gradient data acquired by the Beijing meteorological tower was used to calculate the ground truth aerodynamic roughness length. Then, the optimal dimension of the upwind sector was determined via a correlation analysis between the backscattering coefficient extracted from the SAR data and the corresponding ground truth aerodynamic roughness length determined in the same time and the same direction. And then a quantitative relationship, used to retrieve aerodynamic roughness length from SAR data, was established and the spatial and temporal aerodynamic roughness length in Beijing city was mapped using long term ALOS PALSAR and COSMO-SkyMed data. Our results show the retrieved $z_{0}$ from SAR data could accurately reveal the evolvement of the land use types and the surface roughness elements. Thus the methodology proposed in this paper can provide more accurate input for precise meteorological and climate applications in urban areas. However the limitations of this methodology lie in two aspects. One is that wind gradient data will be needed for quantitative modeling for applications in other cities, and the other is that the fluctuation of the backscattering coefficient of SAR data acquired at different dates will affect the accuracy of the roughness estimation. Aimed at this problem, polarimetric SAR is being studied to seek more stable algorithms for aerodynamic roughness estimation by us because some polarimetric parameters such as double bounce components derived from Freeman and Yamaguchi polarimetric decomposition are more stable indicators to buildings, which are the dominant urban roughness elements.

\section{Competing Interests}

The authors declare that there is no conflict of interests regarding the publication of this paper.

\section{Acknowledgments}

This research was financially supported by National Natural Science Foundation of China (Grant nos. 41671359, 61471358), the Knowledge Innovation Program of the Chinese Academy of Sciences (Grant no. KZCX2-EW-320), National High Technology Research and Development Program of China (863 program) (Grant no. 2011AA120403), the ALOS research program (PI1404), the TanDEM research program (OTHER6984), and the China Scholarship Council (201604910064). Thanks are due to Dr. Junxia Dou for providing information about the meteorological tower.

\section{References}

[1] H. Taubenböck, M. Wiesner, A. Felbier, M. Marconcini, T. Esch, and S. Dech, "New dimensions of urban landscapes: the spatiotemporal evolution from a polynuclei area to a mega-region based on remote sensing data," Applied Geography, vol. 47, pp. 137-153, 2014.
[2] R. D. Crago, W. Okello, and M. F. Jasinski, "Equations for the drag force and aerodynamic roughness length of urban areas with random building heights," Boundary-Layer Meteorology, vol. 145, no. 3, pp. 423-437, 2012.

[3] T. Gál and J. Unger, "Detection of ventilation paths using highresolution roughness parameter mapping in a large urban area," Building and Environment, vol. 44, no. 1, pp. 198-206, 2009.

[4] T. R. Oke, Boundary Layer Climates, John Wiley \& Sons, New York, NY, USA, 1978.

[5] R. Greeley and D. G. Blumberg, "Preliminary analysis of Shuttle Radar Laboratory (SRL-1) data to study aeolian features and processes," IEEE Transactions on Geoscience and Remote Sensing, vol. 33, no. 4, pp. 927-933, 1995.

[6] C. S. B. Grimmond, T. S. King, M. Roth, and T. R. Oke, "Aerodynamic roughness of urban areas derived from wind observations," Boundary-Layer Meteorology, vol. 89, no. 1, pp. 1-24, 1998.

[7] A. Remond and J. P. Deroin, "Empirical and theoretical backscattering behavior as a function of roughness for arid land surfaces," in Proceedings of the IEEE International Geoscience and Remote Sensing Symposium, vol. 4, pp. 1612-1614, 1997.

[8] A. Davenport, C. Grimmond, T. Oke, and J. Wieringa, "Estimating the roughness of cities and sheltered country," in Proceedings of the 12th Conference on Applied Climatology, pp. 96-99, American Meteorological Society, 2000.

[9] M. Zoran, "Remote sensing data for urban air quality assessment," in Proceedings of the Romopto 2000: 6th Conference on Optics, V. I. Vlad, Ed., vol. 4430 of Proceedings of SPIE, pp. 729735, Bucharest, Romania, September 2000.

[10] S. W. Stetson, Surface Roughness and zo Parameter Measured from Satellite-based Synthetic Aperture Radar, Global Environmental Management, Inc., Research Rep, 2004.

[11] S. Bidaut, T. Ranchin, and L. Wald, "Mapping the aerodynamic roughness length using SAR images," in Proceedings of the 25th Symposium of the European Association of Remote Sensing Laboratorie, pp. 145-150, 2006.

[12] L. Basly, F. Cauneau, T. Ranchin, and L. Wald, "ERS SAR imagery for urban climate studies," in Proceedings of the 3rd ERS Symposium on Space at the Service of Our Environment, pp. 233236, Florence, Italy, March 1997.

[13] B. Bechtel, T. Langkamp, F. Ament et al., "Towards an urban roughness parameterisation using interferometric SAR data taking the Metropolitan Region of Hamburg as an example," Meteorologische Zeitschrift, vol. 20, no. 1, pp. 29-37, 2011.

[14] T. Langkamp, Contributions towards a downscaling scheme for urban climate modeling integrating mobile measurements and improved roughness representation for Hamburg [Ph.D. thesis], 2013.

[15] I. Jeyachandran, S. J. Burian, and S. W. Stetson, "Estimating urban canopy parameters using synthetic aperture radar data," Journal of Applied Meteorology and Climatology, vol. 49, no. 4, pp. 732-747, 2010.

[16] G. F. De Grandi, M. Leysen, J. S. Lee, and D. Schuler, "Radar reflectivity estimation using multiple SAR scenes of the same target: technique and applications," in Proceedings of the IEEE International Geoscience and Remote Sensing Symposium (IGARSS '97). Part 1 (of 4), pp. 1047-1050, IEEE, August 1997.

[17] Q. Li, H. Z. Liu, F. Hu, Z. X. Hong, and A. G. Li, "The determination of the aerodynamic parameters over urban land surface," Climatic and Environmental Research, vol. 8, no. 4, pp. 443-450, 2003 (Chinese). 
[18] K. Takagi, A. Miyata, Y. Harazono, N. Ota, M. Komine, and M. Yoshimoto, "An alternative approach to determining zeroplane displacement, and its application to a lotus paddy field," Agricultural and Forest Meteorology, vol. 115, no. 3-4, pp. 173181, 2003.

[19] C. Y. Zhu, R. H. Zhang, J. F. Wang, X. M. Sun, and Z. L. Zhu, "Mapping of the aerodynamic roughness using SAR and TM images," Science in China Series D, vol. 4, no. 4, pp. 385-393, 2004 (Chinese).

[20] F. Hu, Turbulence, Intermittence and Atmospheric Boundary Layer, Science Press, Beijing, China, 1995.

[21] H. S. Zhang and J. Y. Chen, "Estimation of aerodynamic parameters on non-single horizontal homogeneous underlying surface," Quarterly Journal of Applied Meteorology, vol. 8, no. 3, pp. 310-315, 1997.

[22] Z. Q. Gao, L. G. Bian, C. G. Lu, L. H. Lu, J. X. Wang, and Y. Wang, "Estimation of aerodynamic parameters in urban areas," Journal of Applied Meteorological Science, vol. 13, pp. 26-33, 2002 (Chinese).

[23] Y. Q. Ju, Study of Aerodynamic Roughness Length and Thermal Roughness Length on Different Underlying Surface, Nanjing University of Information Science and Technology, Nanjing, China, 2012 (Chinese). 

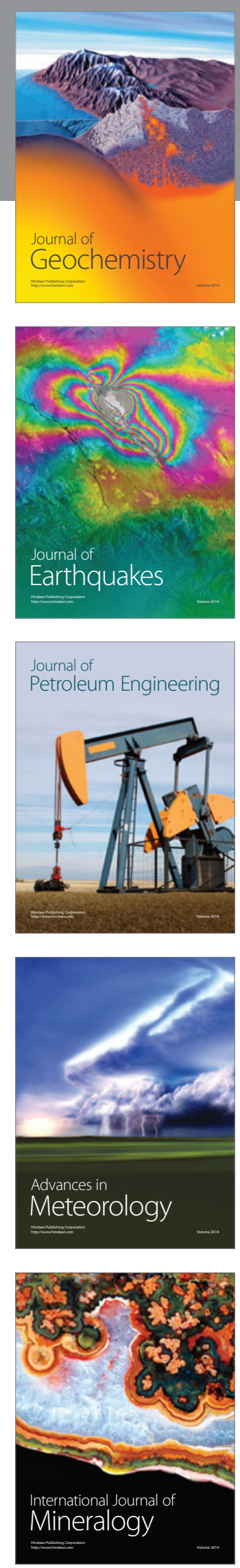
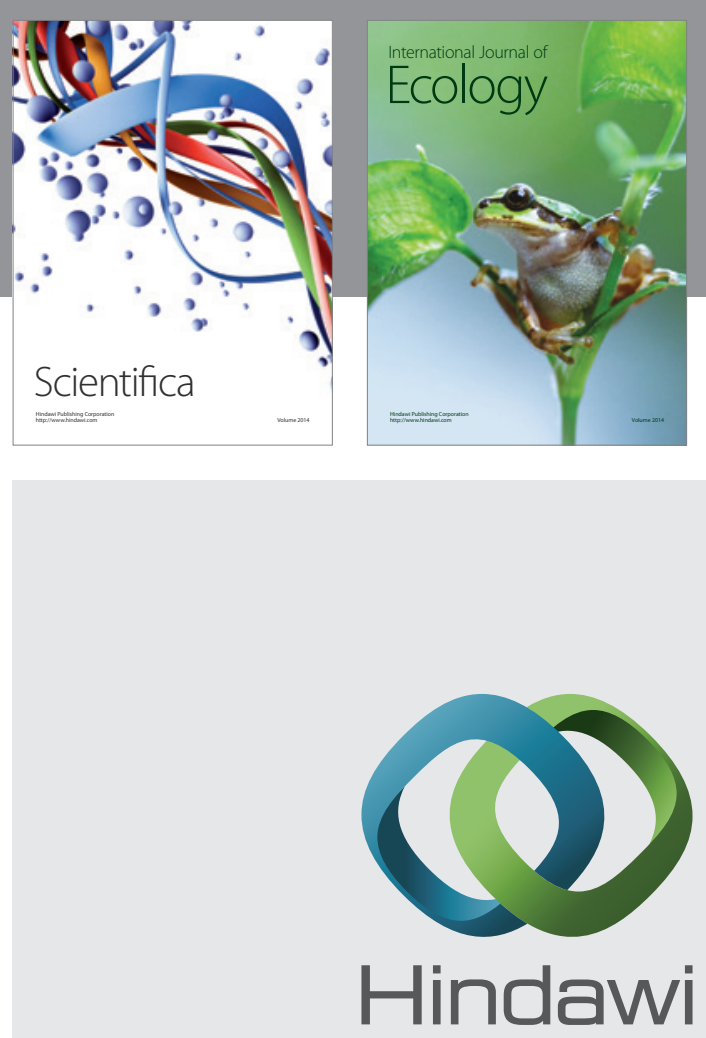

Submit your manuscripts at

https://www.hindawi.com
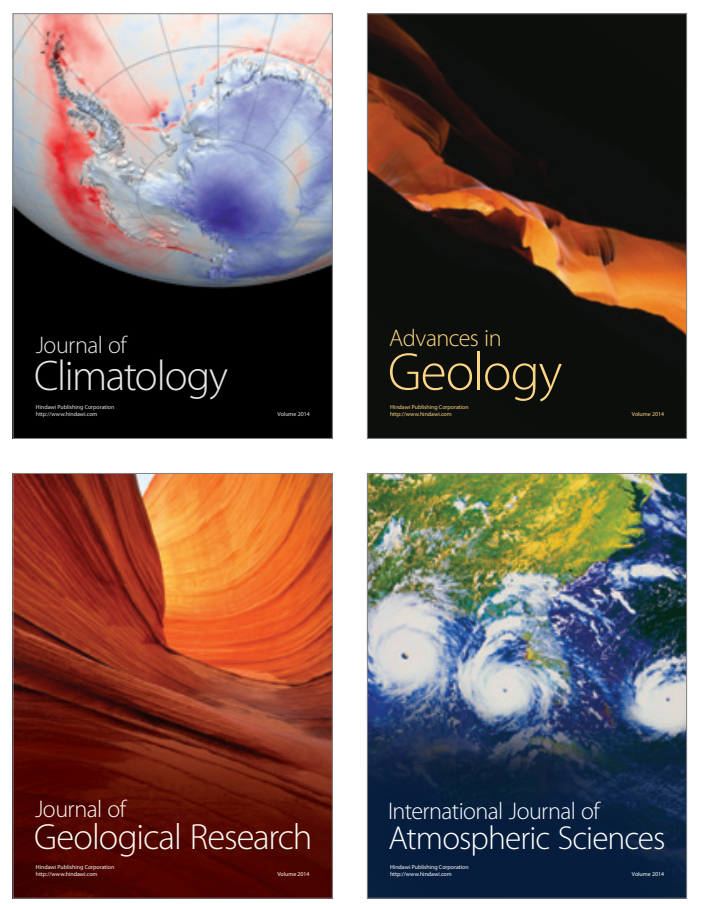

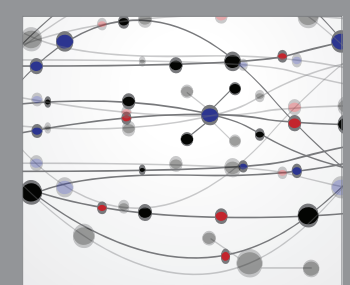

The Scientific

\section{World Journal}
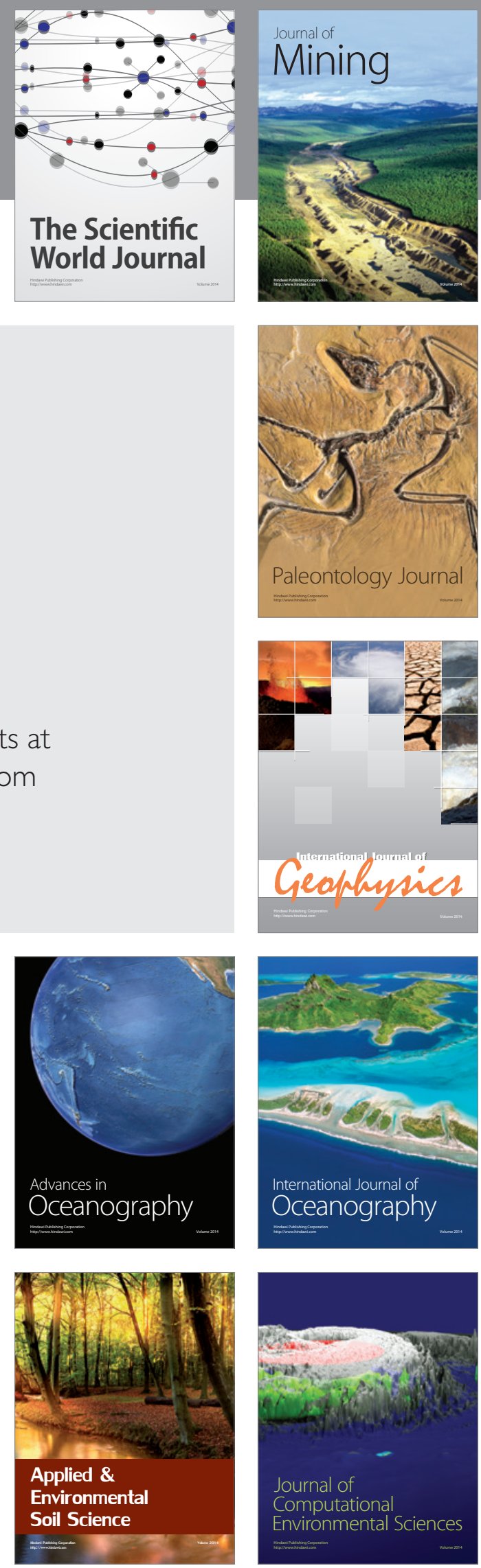